\title{
LOW-GRADE INFLAMMATION IN SUBCLINICAL HYPOTHYROIDISM: ROLE OF HIGH- SENSITIVE C-REACTIVE PROTEIN
}

\author{
PRADEEP KUMAR ${ }^{1}$, PREETI SHARMA ${ }^{1 *}$, RACHNA SHARMA ${ }^{2}$, GAURAV GUPTA ${ }^{3}$, ANCHAL CHAUDHARY ${ }^{1}$
}

${ }^{1}$ Department of Biochemistry, Santosh Medical College and Hospital, Ghaziabad, Uttar Pradesh, India. ${ }^{2}$ Department of Biochemistry, TSM Medical College and Hospital, Lucknow, Uttar Pradesh, India. ${ }^{3}$ Department of Biochemistry, Govt. Medical College and Hospital, Badaun, Uttar Pradesh, India. Email: prcdri2003@yahoo.co.in

Received: 20 April 2018, Revised and Accepted: 01 June 2018

ABSTRACT

Objective: Subclinical hypothyroidism $(\mathrm{SCH})$ patients may present with abnormal lipid profile more specifically in patients having thyroid-stimulating hormone (TSH) $>10 \mathrm{mIU} / \mathrm{L}$. Since the contradiction still lies with patients having TSH $<10 \mathrm{mIU} / \mathrm{L}$, so the role of high-sensitive C-reactive protein (HsCRP) may be important with the prediction of inflammatory cardiovascular risk.

Methods: Recently diagnosed $30 \mathrm{SCH}$ patients both male and female were recruited and compared 30 normal healthy adults. Age and body mass index (BMI) of the study population were noted. Thyroid profile including TSH, FT4, and T3 was measured by an enzyme-linked immunosorbent assay (ELISA). Total cholesterol, triglycerides, and high-density lipoprotein (HDL) cholesterol were measured by the CHOD-POD method, GPO-PAP method, and CHOD-POD/phosphotungstic method. Low-density lipoprotein (LDL) cholesterol and very low-density cholesterol were measured by Friedewald formula. Lipoprotein ratios were also calculated. An ELISA was also used for the estimation of Hs-CRP.

Results: The significant results were obtained in this study. BMI was significantly $(<0.01)$ elevated in patients' group compared to the control group. In the thyroid profile, TSH was significantly $(<0.05)$ different between the groups. Total cholesterol, triglycerides, and LDL-cholesterol were significantly $(<0.01)$ elevated in the case group. A significantly lower concentration of HDL cholesterol was observed in SCH patients when compared with control subjects. There was an elevated concentration of lipoprotein ratios in patients group. The mean concentration of Hs-CRP was highly significant between the groups. The level was higher in the case group compared to the control group. In patients' group, there was a positive association ( $\beta$ 0.36) (confidence interval 95\%-0.002-0.536) between TSH and Hs-CRP. This association was highly significant.

Conclusion: SCH patients having TSH $<10 \mu \mathrm{IU} / \mathrm{ml}$ were characterized by dyslipidemia and elevated Hs-CRP. Increased lipoprotein ratios and Hs-CRP may promote low-grade inflammation in SCH patients, by which cardiovascular risk can be developed.

Keywords: Dyslipidemia, Cardiovascular risk, Acute inflammation.

(c) 2018 The Authors. Published by Innovare Academic Sciences Pvt Ltd. This is an open access article under the CC BY license (http://creativecommons. org/licenses/by/4. 0/) DOI: http://dx.doi.org/10.22159/ajpcr.2018.v11i9.26807

\section{INTRODUCTION}

Subclinical hypothyroidism (SCH) is the most common endocrine disease worldwide. SCH is characterized by an elevated concentration of thyroid-stimulating hormone (TSH) above the reference range and normal concentration of free thyroxine (FT4) and triiodothyronine (T3) [1]. SCH is a biochemical disorder rather than clinical disorder since patients with $\mathrm{SCH}$ are generally asymptomatic or present with non-specific symptoms of overt hypothyroidism. Hence, the patients are diagnosed with $\mathrm{SCH}$ on the basis of thyroid profile picture [2]. Studies in the past have evaluated that the presence of dyslipidemia may not be neglected in patients, more specifically in moderate $\mathrm{SCH}$ having TSH $>10 \mathrm{mIU} / \mathrm{L}$, but the results were contradictory [3,4]. Since the presence of dyslipidemia may suggest future progression of cardiovascular risks, the role of inflammatory markers may be important in $\mathrm{SCH}$ patients because without inflammation cholesterol cannot be trapped [5,6]. High-sensitive C-reactive protein (Hs-CRP), a diagnostic tool for assessment of cardiovascular disease, is a marker of low-grade inflammation, which may lead to atherosclerosis [7]. Estimation of Hs-CRP may be valuable since it is an effective marker for heart diseases rather than low-density lipoprotein (LDL) cholesterol alone [8]. Hs-CRP may evaluate the status of low-grade inflammation in patients with SCH. Therefore, the main objective of this study was to an assessment of Hs-CRP in SCH patients having $\mathrm{TSH}<10 \mathrm{mIU} / \mathrm{l}$ along with lipid profile.

\section{METHODS}

This cross-sectional study was carried out in the Department of Biochemistry, Santosh Medical College and Hospital, Ghaziabad. All the participants voluntarily participated in this study. Written consent was obtained from each individual. This study was ethically approved by the institutional ethical committee. 30 recently diagnosed SCH patients were enrolled for the study and compared with age and sex-matched 30 normal healthy controls. Fasting blood samples were obtained from each participant.

Exclusion criteria

1. Patients having personal or family history of thyroid disease and medication.

2. Patients having a history of cardiovascular disease, hypertension, diabetes, renal disorder, and liver disease.

3. Pregnant women or having past 2-year history of pregnancy and women with menopause.

4. A person using social habits, for example, tobacco, smoking, and alcoholics.

5. Patients suffering from any inflammatory disease, for example, periodontitis and rheumatoid arthritis.

\section{Inclusion criteria}

Recently diagnosed SCH patients were included and normal healthy adults were included in the study. The age group criterion for this study was from 20 to 45 years. 


\section{Methods}

Baseline parameters including age and body mass index (BMI) were noted. BMI was calculated, dividing weight in a kilogram of an individual with the square of the height of that individual in the meter [9]. Blood parameters (TSH, FT4, T3, total cholesterol [TC], triglycerides [TGs], high-density lipoprotein [HDL] cholesterol, LDL-cholesterol, very lowdensity lipoprotein [VLDL], lipoprotein ratios, and Hs-CRP) were also measured. SCH patients were having elevated concentration of TSH $(>6.0 \mu \mathrm{IU} / \mathrm{ml}$ ) along with normal concentrations of thyroid hormones. Thyroid profile including TSH, FT4, and T3 wasss measured by an enzyme-linked immunosorbent assay (ELISA) [10]. TC, TG, and HDLcholesterol were measured by CHOD-POD method, GPO-PAP method, and CHOD-POD/phosphotungstic method [11]. LDL-cholesterol and VLDL were measured by Friedewald formula [12]. Lipoprotein ratios including TC/HDL-cholesterol and LDL-cholesterol/HDL-cholesterol were also calculated [11]. Hs-CRP was also measured by ELISA method [13].

\section{Statistical analysis}

All the variables were expressed in mean \pm SD. An unpaired student's t-test was applied to the groups to differentiate various parameters. A linear regression analysis was used for association between TSH and $\mathrm{Hs}-\mathrm{CRP}$ in $\mathrm{SCH}$ patients. A p $<0.05$ was considered statistically significant. The statistical software Statistical package for the Social Science version 20.0 was used for statistical analysis.

\section{RESULTS}

In this study, significant results were obtained. BMI was higher in $\mathrm{SCH}$ group compared to control group. The result was highly significant $(<0.01)$. In thyroid profile, TSH was significantly $(<0.01)$ different between the groups (Table 1). In lipid profile, elevated concentration of the TC, TG, LDL cholesterol, and VLDL was higher in SCH patients. These higher concentrations were significantly $(<0.05)$ different when compared with control group. HDL cholesterol was significantly $(<0.01)$ higher in the control group compared to $\mathrm{SCH}$ group. Lipoprotein ratios including TC/HDL-cholesterol and LDL-cholesterol/HDL-cholesterol were significantly $(<0.01)$ higher in SCH group. Serum concentration of Hs-CRP was significantly $(<0.01)$ different between the groups (Fig. 1). The level of Hs-CRP was higher in SCH group (Table 2). There was a significant positive association between TSH and Hs-CRP in SCH patients (Table 3).

\section{DISCUSSION}

$\mathrm{SCH}$ patients are generally asymptomatic or present with few to various symptoms of overt hypothyroidism [14]. Patients with SCH in this study are characterized by the presence of dyslipidemia, which is the basic reason for developing cardiovascular disease [15]. Weight gain is quite common in hypothyroidism [16], and it is also observed in SCH patients since they are characterized with increased BMI when compared to normal healthy adults. Gupta et al. supported this finding by suggesting a positive association between TSH and BMI during a study on SCH women [17]. There was an elevated concentration of TC and LDL cholesterol in SCH patients. In support of this, Hueston and Pearson reported the presence of hypercholesterolemia in patients with SCH [18]. In comparison to this, mean concentration of HDL-cholesterol was lower in SCH group compared to control group. Erdem et al. also supported this result when observed a negative association between HDLcholesterol and TSH [19]. TG an important component of metabolic syndrome also found to be higher in patients with $\mathrm{SCH}$ compared to control group [20]. In addition to this, Marwaha et al. reported that dyslipidemia is present in SCH patients having TSH $>10 \mathrm{mIU} / \mathrm{L}$, not in patients with TSH $<10 \mathrm{mIU} / \mathrm{L}$ [21]. However, in this study, elevated concentrations of lipid parameters were observed which is supported by Regmi et al. when they suggested that the risk of cardiovascular disease may not be avoided in SCH patients having $\mathrm{TSH}<10 \mathrm{mIU} / \mathrm{L}$ and these patients should be treated with caution due to the presence of dyslipidemia [22]. It was also stated that
Table 1: Baseline parameters between SCH and control group

\begin{tabular}{lllll}
\hline S. No. & Parameters & SCH group & Control group & p value \\
\hline 1. & Age & $34.50 \pm 3.25$ & $35.0 \pm 3.35$ & $>0.05$ \\
2. & BMI & $26.44 \pm 2.19$ & $21.98 \pm 1.40$ & $<0.01$ \\
3. & TSH & $8.47 \pm 1.20$ & $1.81 \pm 0.41$ & $<0.01$ \\
4. & FT4 & $1.20 \pm 0.29$ & $1.19 \pm 0.25$ & $>0.05$ \\
5. & T3 & $0.94 \pm 0.12$ & $1.06 \pm 0.30$ & $<0.05$ \\
\hline
\end{tabular}

Variables were expressed in Mean \pm SD. A $p<0.05$ was statistically significant. SCH: Subclinical hypothyroidism, TSH: Thyroid-stimulating hormone, BMI: Body mass index

Table 2: Lipid profile and Hs-CRP between the groups

\begin{tabular}{lllll}
\hline S. No. & Parameters & SCH group & Control group & p value \\
\hline 1. & TC & $197.04 \pm 19.81$ & $185.73 \pm 9.52$ & $<0.01$ \\
2. & TG & $117.93 \pm 23.95$ & $105.00 \pm 22.27$ & $<0.05$ \\
3. & HDL-C & $43.16 \pm 3.17$ & $47.46 \pm 4.15$ & $<0.01$ \\
4. & LDL-C & $128.68 \pm 19.91$ & $117.48 \pm 10.04$ & $<0.01$ \\
5. & VLDL & $23.66 \pm 4.80$ & $20.97 \pm 4.49$ & $<0.05$ \\
6. & TC/HDL-C & $4.57 \pm 0.50$ & $3.95 \pm 0.40$ & $<0.01$ \\
7. & LDL-C/HDL-C & $2.99 \pm 0.51$ & $2.49 \pm 0.35$ & $<0.01$ \\
8. & Hs-CRP & $3.03 \pm 0.37$ & $1.63 \pm 0.38$ & $<0.01$ \\
\hline
\end{tabular}

Variables were expressed in Mean \pm SD. A $p<0.05$ was statistically significant. Hs-CRP: High-sensitive C-reactive protein, LDL-C: Low-density lipoprotein cholesterol, HDL-C: High-density lipoprotein cholesterol, VLDL: Very Low-density lipoprotein cholesterol, TC: Total cholesterol, TGs: Triglycerides, SCH: Subclinical hypothyroidism

Table 3: An association between TSH and Hs-CRP in SCH group

\begin{tabular}{lllll}
\hline Group & Standardized $\beta$ & \multicolumn{2}{c}{ CI 95\% } & \multirow{2}{*}{ p value } \\
\cline { 3 - 4 } & & Lower & Upper & \\
\hline SCH & 0.363 & 0.002 & 0.536 & $<0.05$ \\
\hline
\end{tabular}

By linear regression analysis, a $P$ value $<0.05$ was statistically significant. $\mathrm{SCH}$ Subclinical hypothyroidism, Hs-CRP: High-sensitive C-reactive protein, TSH: Thyroid-stimulating hormone, CI: Confidence Interval

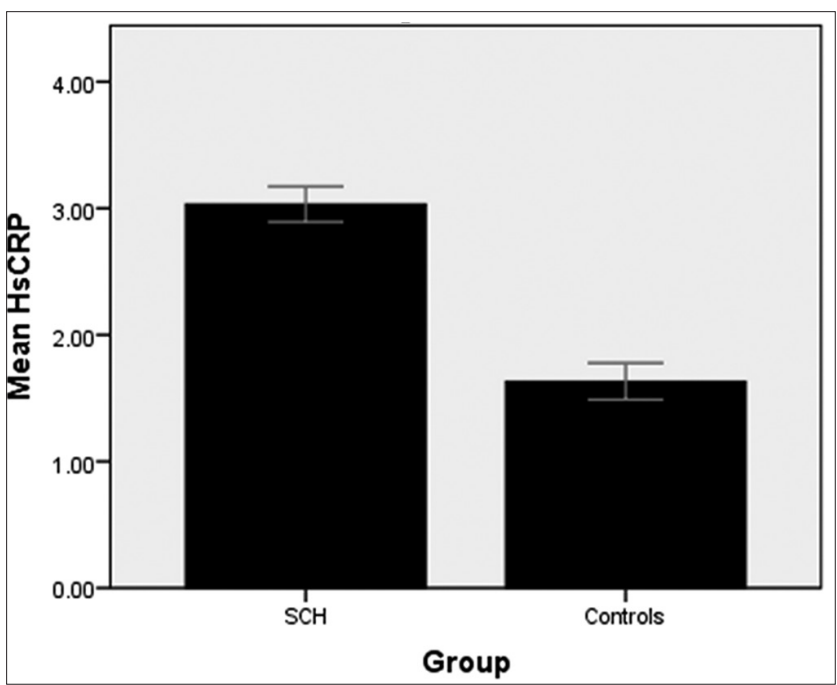

Fig. 1: Bar diagram representing the concentration of mean high-sensitive C-reactive protein with standard error between subclinical hypothyroidism and control group

although the developing risk of cardiovascular disease was greater in SCH patients having TSH $>10 \mu \mathrm{IU} / \mathrm{ml}$, consideration should also be given to the patients having $\mathrm{TSH}<10 \mu \mathrm{IU} / \mathrm{ml}$ [23]. Lipoprotein ratios including TC/HDL-cholesterol and LDL cholesterol/HDL cholesterol are the better predictor of cardiovascular risk and atherosclerosis 
than any other single lipid parameter [24]. There was an increased concentration of TC/HDL-cholesterol ratio and LDL cholesterol/ HDL-cholesterol ratio in patients with $\mathrm{SCH}$ compared to control group. Increased LDL-cholesterol/HDL-cholesterol ratio along with elevated TGs may predict the risk of ischemic heart disease [25]. Kvetny et al. also found that hypertriglyceridemia was associated with $\mathrm{SCH}$ males $<50$ years and indicated the sign of low-grade inflammation by an elevated concentration of Hs-CRP [26]. SCH patients may promote low-grade inflammation and develop the cardiovascular risk in future. CRP may account for additional factor for atherosclerosis in SCH patients [27]. Elevated concentration of Hs-CRP in this study also supported this finding. Gupta et al. reported the findings on SCH male patients with increased concentration CRP and other inflammatory markers and stated that SCH patients are characterized by cardiovascular abnormalities [28]. The presence of dyslipidemia in SCH patients including the elevated concentration of TC, increased TG, lower HDL-cholesterol, and abnormal LDLcholesterol along with the increased concentration of Hs-CRP can lead to the development of atherosclerosis [29]. Tuzcu et al. also reported similar findings in terms of LDL-cholesterol and Hs-CRP in $\mathrm{SCH}$ patients and suggested that low-grade inflammation may be promoted by an elevated concentration of Hs-CRP [30]. A study from a Taiwanese population also found a positive association between SCH and elevated quartiles of Hs-CRP [31]. Increased concentration of Hs-CRP and elevated lipoprotein ratios may predict the risk of cardiovascular disease in SCH patients [32].

\section{CONCLUSION}

The outcomes of this cross-sectional study revealed that there is an increased concentration of lipid parameters in patients with mild hypothyroidism having $\mathrm{TSH}<10 \mu \mathrm{IU} / \mathrm{ml}$. Elevated lipoprotein ratios may suggest the developing risk of atherosclerosis in SCH patients. Higher concentration of Hs-CRP suggests the presence of low-grade inflammation, which may be the sign of developing cardiovascular abnormalities in patients with SCH. On concluding, patients with SCH having TSH $<10 \mu \mathrm{IU} / \mathrm{ml}$ should be treated with caution and monitored carefully.

\section{Limitations}

Since it was an short-term studentship (STS) project for a limited time period, the only limitation of this study was its sample size. Hence, the more studies should be conducted with large sample size along with others establish marker to confirm this association.

\section{ACKNOWLEDGMENT}

The authors are very thankful to the Indian Council of Medical Research (ICMR) for supporting our study while giving STS. We are also very thankful for supporting staff of the Department of Biochemistry of Santosh Medical College and Hospital, Ghaziabad, for their support to conduct this hassle-free research.

\section{CONFLICTS OF INTEREST}

The authors have no conflicts of interest.

\section{AUTHOR'S CONTRIBUTION}

Dr. Pradeep Kumar and Dr. Preeti Sharma gave the concept of this study. The study design was done by Dr. Preeti Sharma, Dr. Rachna Sharma, and Dr. Gaurav Gupta. All the practical work was done by Ms Anchal Chaudhary. The statistical analysis was done by Dr. Gaurav Gupta. The writing, as well as editing, was done by Dr. Preeti Sharma, Dr. Rachna Sharma, and Dr. Gaurav Gupta.

\section{REFERENCES}

1. Hebbar S, Kumar S, Amin S, Doizode S. Subclinical hypothyroidism in pregnancy; is there a need for pharmacological intervention? Int $\mathrm{J}$ Pharm Pharm Sci 2017;9:186-91

2. Rugge B, Balshem H, Sehgal R, Relevo R, Gorman P, Helfand M.
Screening and Treatment of Subclinical Hypothyroidism or Hyperthyroidism. Rockville (MD): Agency for Healthcare Research and Quality (US). Comparative Effectiveness Reviews, No 24;

3. Fiarresga AJ, Feliciano J, Fernandes R, Martins A, Pelicano N, Timóteo AT, et al. Relationship between coronary disease and subclinical hypothyroidism: An angiographic study. Rev Port Cardiol 2009;28:535-43.

4. Toruner F, Altinova AE, Karakoc A, Yetkin I, Ayvaz G, Cakir N, et al. Risk factors for cardiovascular disease in patients with subclinical hypothyroidism. Adv Ther 2008;25:430-7.

5. Tall AR, Charvet LY. Choleterol, inflammation and innate immunity. Nat Rev Immunol 2015;15:104-16.

6. Gupta G, Sharma P, Kumar P, Sharma R. Role of inflammatory markers in subclinical hypothyroidism. Asian J Pharm Clin Res 2015;8:24-7.

7. Saad EA, Habib SA, Refai WA, Elfayoumy AA. Malondialdehyde, adiponectin, nitric oxide, C-reactive protein, tumor necrosis factoralpha and insulin resistance relationships and inter-relationships in Type 2 diabetes early stage. Is metformin alone adequate in this stage? Int J Pharm Pharm Sci 2017;9:176-81.

8. Datta S, Iqbal Z, Prasad KR. Comparison between serum Hs-CRP and LDL cholesterol for search of a better predictor for ischemic heart disease. Indian J Clin Biochem 2011;26:210-3.

9. Nuttall FQ. Body mass index: Obesity, BMI, and health: A critical review. Nutr Today 2015;50:117-28.

10. Gan SD, Patel KR. Enzyme immunoassay and enzyme-linked immunosorbent assay. J Invest Dermatol 2013;133:e12.

11. Rifai N, Warnick GR, Remaley AT. Lipids, lipoproteins, apolipoproteins, and other cardiovascular risk factors. In: Burtis CA, Ashwood ER, Bruns DE, editors. Teitz Fundamentals of Clinical Chemistry. Pennsylvania: Saunders an Imprint of Elsevier Inc.; 2010. p. 422-4.

12. Friedewald WT, Levy RI, Fredrickson DS. Estimation of the concentration of low-density lipoprotein cholesterol in plasma, without use of the preparative ultracentrifuge. Clin Chem 1972;18:499-502.

13. Shine B, De Beer FC, Pepys MB. Solid phase radioimmunoassay for human C-reactive protein. J Lab Clin Chim Acta 1981;117:13-23.

14. Pearce SH, Brabant G, Duntas LH, Monzani F, Peeters RP, Razvi S, et al 2013 ETA guideline: Management of subclinical hypothyroidism. Eur Thyroid J 2013;2:215-28.

15. Maleki N, Kazerouni F, Hedayati M, Rahimipour A, Parham M. Subclinical hypothyroidism and the alterations of lipid profile as a cardiovascular risk factor. JPS 2015;6:20-5.

16. Longhi S, Radetti G. Thyroid function and obesity. J Clin Res Pediatr Endocrinol 2003;5:40-4.

17. Gupta G, Sharma P, Kumar P, Itagappa M, Sharma R. A correlation between thyroid stimulating hormone and body mass index in women with subclinical hypothyroidism. Asian J Pharm Clin Res 2015;8:206-8.

18. Hueston WJ, Pearson WS. Subclinical hypothyroidism and the risk of hypercholesterolemia. Ann Fam Med 2004;2:351-5.

19. Erdem TY, Ercan M, Ugurlu S, Balci H, Acbay O, Gundogdu S, et al. Plasma viscosity, an early cardiovascular risk factor in women with subclinical hypothyroidism. Clin Hemorheol Microcirc 2008;38:219-25.

20. Milionis HJ, Tambaki AP, Kanioglou CN, Elisaf MS, Tselepis AD, Tsatsoulis A, et al. Thyroid substitution therapy induces high-density lipoprotein-associated platelet-activating factor-acetylhydrolase in patients with subclinical hypothyroidism: A potential antiatherogenic effect. Thyroid 2005;15:455-60.

21. Marwaha RK, Tandon N, Garg MK, Kanwar R, Sastry A, Narang A, et al. Dyslipidemia in subclinical hypothyroidism in an Indian population. Clin Biochem 2011;44:1214-7.

22. Regmi A, Shah B, Rai BR, Pandeya A. Serum lipid profile in patients with thyroid disorders in central Nepal. Nepal Med Coll J 2010;12:253-6.

23. Gupta G, Sharma P, Kumar P, Sharma R. Cardiovascular risk in patients with mild to severe subclinical hypothyroidism. Asian J Pharm Clin Res 2016;9:168-70

24. Millán J, Pintó X, Muñoz A, Zúñiga M, Rubiés-Prat J, Pallardo LF, et al. Lipoprotein ratios: Physiological significance and clinical usefulness in cardiovascular prevention. Vasc Health Risk Manag 2009;5:757-65.

25. Stampfer MJ, Krauss RM, Ma J, Blanche PJ, Holl LG, Sacks FM, et al. A prospective study of triglyceride level, low-density lipoprotein particle diameter, and risk of myocardial infarction. JAMA 1996;276:882-8.

26. Kvetny J, Heldgaard PE, Bladbjerg EM, Gram J. Subclinical hypothyroidism is associated with a low-grade inflammation, increased triglyceride levels and predicts cardiovascular disease in males below 50 years. Clin Endocrinol (Oxf) 2004;61:232-8. 
27. Gupta G, Sharma P, Kumar P, Itagappa M. Study on subclinical hypothyroidism and its association with various inflammatory markers. J Clin Diagn Res 2015;9:BC04-6.

28. Gupta G, Sharma P, Kumar P, Sharma R. Is cardiovascular risk associated with subclinical hypothyroidism: Role of $\mathrm{C}$ reactive protein and interleukin-6. J Cardiovasc Disease Res 2018;9:20-3

29. Christ-Crain M, Meier C, Guglielmetti M, Huber PR, Riesen W, Staub JJ, et al. Elevated C-reactive protein and homocysteine values: Cardiovascular risk factors in hypothyroidism? A crosssectional and a double-blind, placebo-controlled trial. Atherosclerosis $2003 ; 166: 379-86$.
30. Tuzcu A, Bahceci M, Gokalp D, Tuzun Y, Gunes K. Subclinical hypothyroidism may be associated with elevated high-sensitive c-reactive protein (low grade inflammation) and fasting hyperinsulinemia. Endocr J 2005;52:89-94.

31. Yu YT, Ho CT, Hsu HS, Li CI, Davidson LE, Liu CS, et al. Subclinical hypothyroidism is associated with elevated high sensitive $\mathrm{C}$ reactive protein in among adult Taiwanese. Endocrine 2013;44:716-22.

32. Mahto M, Chakraborthy B, Gowda SH, Kaur H, Vishnoi G, Lali P, et al. Are Hs-CRP levels and LDL/HDL ratio better and early markers to unmask onset of dyslipidemia and inflammation in asymptomatic subclinical hypothyroidism? Indian J Clin Biochem 2012;27:284-9. 